\title{
Developing An Orientation Program For Faculty Who Teach In Cohort-Based Programs
}

Gerri F. Luke, (E-mail: gluke@ dejazzd.com), Strategic Innovations in Education Anthony Fabrizio, (E-mail: ANFA@ecco.com), Southern New Hampshire University

\begin{abstract}
In recent years, adult educators have seen the surge of cohort-based programs. This phenomenon has created many challenges for faculty. This paper will provide an overview of the development of a faculty orientation program and discuss the challenges of facilitating within a cohort-based program.
\end{abstract}

\subsection{Introduction}

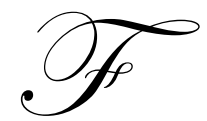

or decades, many adults have found a need to return to school: to seek self-fulfillment, to achieve economic well-being, and to gain needed skills. According to the American Council on Education (ACE), adult students (twenty-five years or older) have been flooding American colleges and universities in larger and larger numbers since World War II (Luke, 2002). While Joseph Kett (1994) has stated that Americans placed great value on the autodidact, in recent years, adult educators have seen the surge of cohort-based programs. This new phenomena has created challenges for instructors who teach in accelerated programs that are often cohort-based. In the mid-nineties, the authors joined a small college that had introduced a cohort-based degree completion program several years prior. During the inception of the program, a group of consultants had introduced and trained faculty to the pedagogical nuances of teaching in a cohort-based degree completion program. Over the ensuing years, curriculum needed updating and adjunct faculty had wondered in and out of the program necessitating on-going orientations and training.

Since adult students are not easily categorized as a group as are traditional age students, educators face many difficulties when designing appropriate environments to service them. MacKinnon-Slaney leads us to believe that there are no common factors that influence the success of adults, that their

satisfaction with and continued participation in formal learning are not the consequences of one easily isolated factor in the interactionist paradigm, but rather complicated responses to a series of issues confronted by the individual adult in his or her unique situation as a "universe of one" (MacKinnon-Slaney, 1994, p. 269).

As a result, educators and faculty are often left wondering how best to approach the many and varied eclectic groups that sit before them in each class. Coupled with the unique and varied backgrounds of each adult student are the challenges of assuring students in accelerated cohort-based programs are provided a quality educational experience. Teachers and administrators must consider: what is the philosophy and purpose of this program? How does one facilitate when one feels responsible to assure the information is delivered and absorbed? How does one clarify the roles of facilitator and students? What techniques work best in cohort-based programs? How does one faculty member deal with the demands of a unified cohort -- especially when these demands run counter to the values or expectations of the teacher?

The literature on the adult student suggests the need for an interactionist approach as presented by MacKinnon-Slaney, one that considers the possibility that adult experiences offer opportunities for learning and "potential development into something more than what already exists" (1994, p.272). Further, Dewey had inspired 
some educators of adults to become "more cognizant of the environment of learning and of the structuring of the learning experience to more closely relate to the adult's actual experienced life" (Rose, 1996, p. 5). Daily, adults find themselves forced to take part in the on-going dialogue essential to their work, families, and communities. The cohort experience encourages similar interactive relationships reflective of the adult's real world experience and thus presents a powerful model to consider the context of the adult experience as it further interacts with learning to support a transformation of the adult student's individual perspective and belief structures.

Armed with this belief, we approached the idea of developing an on-going orientation, one that would be required for all new faculty and one that would require veteran faculty to attend on some rotating basis. One of the authors held the position of Dean of the program and struggled to clarify the critical need of updating the program and renewing the teaching approach. When she initially accepted the position, she was told that enrollments had dipped. During meetings with groups of students, faculty and staff, she continually heard issues with inconsistent teaching methods and curriculum that had become outdated. Clearly, a renewal was needed -- one that would include existing faculty while simultaneously offering new faculty an introduction to the program and the essential support to learn new pedagogical approaches. The thought was that the veteran faculty would contribute to the learning process of the newer faculty while also renewing their own approaches. In addition, we wanted to establish a culture that accepted this on-going renewal of pedagogical approaches and development of curriculum. That, we knew, would not be accomplished with merely one orientation required when one first began to teach in the program.

The highest priority was a review of the curriculum. Thus, the first faculty meetings revolved around this need and the establishment of a committee to address the issues. Since the majority of faculty were adjunct and held full-time jobs, establishing meeting times was difficult. However, it was clear that the influx of new administrators and faculty was establishing this culture of on-going renewal. Meetings were well attended by new faculty as well as older faculty who agreed with the need for change. Those who resisted the change failed to find the essential time to contribute to the process and soon stopped teaching in the program. The time and day that attracted the largest attendance was Friday mornings. Breakfast was served, and faculty quickly began to establish the same bond that many of the cohorts of students were experiencing. First, the committee established priorities: identify lead faculty for each course; review and rewrite, if needed, the curriculum of each course; establish a rotating timeframe for each course to be reviewed; come to an understanding of the philosophy of the degree-completion program; develop an orientation/workshop; require all new faculty to attend prior to beginning as a faculty member; and develop a rotating schedule for veteran faculty to attend these orientations/workshops.

\subsection{Curriculum Renewal and Review}

Many meetings revolved around the curriculum. Each course was considered and discussed in depth by faculty from all disciplines. It was accepted that the courses needed to be integrative to the whole program. While assuring that each course could stand on its own, the accelerated nature of the program required the linking of each course. Obviously, the flow or placement of each course was critical to the success of such integration. For example, a marketing course would be designed to aid in the development of the marketing plan for the final project, the creation of a new business. Moreover, before cohorts could work effectively, they needed to learn about teams. The first two courses explored the development of teams, group process and the establishing of structures and procedures for each group. Later, many students told us that it was not until the end of the cohort experience and the creation of their final project that they finally realized the most important courses they had taken were the first two.

Once the committee had agreed on the appropriate sequence, faculty were identified as lead faculty responsible for the on-going review and rewriting of each course. New and veteran faculty who taught each course were told to contact lead faculty to discuss any thoughts or recommendations to either curriculum content or pedagogical approaches to individual courses. This provided all new faculty with a contact or mentor for their course. In addition, a timetable was established for the review of each course. Faculty agreed on which courses needed review immediately and which could wait. It was also agreed that rewritten courses would be introduced to the faculty as a whole at regular faculty meetings. Faculty had communicated the feeling of isolation when they 
were not aware of what was being taught or emphasized in courses they did not teach. Once the timeframe for the curriculum review was established, the committee set about designing the orientation.

\subsection{Development of Program Philosophy, Vision, and Goals}

Now, it was time to agree on how we would orient the faculty to the facilitator's role. The facilitator in each class would be most responsible for assuring the group process was effective. As each new facilitator enters a cohort, it is essential to review the structures and practices needed or already in place to help individual cohorts meet their own goals and those of the academic program. While this process should have been established upfront, facilitators are aware that each new class brings an opportunity to review and adjust the structures and practices. While degree-completion programs have become prolific throughout the country, resistance to the shortened terms as well as the controlled curriculum still exists among more traditional faculty. Thus, we thought it was important to develop and agree upon a philosophical approach to the program. We needed to understand what we hoped we were accomplishing and how we would accomplish it. A small group of approximately ten faculty and administrators met to discuss their philosophical approach to the program. A veteran faculty member, one who had once served as a full-time faculty member at the College but had since left to establish his own business, facilitated these meetings. His only connection to the College was his on-going commitment and belief in the power of this degree-completion program. His facilitation of these meetings served as a model for the manner in which we felt all program classes should be taught. MacKinnon-Slaney's quote referenced earlier was introduced to begin the discussion. After several meetings, the committee agreed on the following:

The program should support learning through:

口 respect for the individuality of the learner;

口 individualization of learning process to support differing learning styles;

口 creation of a learning environment that is intellectually challenging, highly professional, and emotionally safe;

a and activities that encourage effective interaction and support between members of the learning community.

It was proposed and accepted that this purpose and philosophy would guide all development of policy, procedures, and behavior for all involved with the program. In other words, policy, procedure, and behavior should be consistent with the purpose and philosophy of the program as defined by the faculty.

As the vision evolved, it mirrored the committee's philosophy. Through this process, the committee had come to recognize the difficulty of delivering a program that proposed to effectively develop teams while simultaneously recognizing the individualization of each student. Our feeling was that our "problem" mirrored that of the business world as well as of society. It was agreed that faculty needed to understand their own limitations and perspectives to develop a teaching plan that would draw on the broad array of experiences and perspectives within each cohort. The teacher, then, became a facilitator of the learning process.

For some, this was a perspective change in itself. This would allow us to learn from each other and through this integration of our experiences help each other evolve. Our goal was to present the opportunity for a similar perspective change for each of our students. In addition, to accomplish this, we needed to respect the varied learning styles recognized by Gardner (1990) and many other educators. After much discussion, the following was introduced to the entire faculty at the next faculty meeting and to new faculty during each orientation program.

Vision

The program will emphasize the support of learning while placing a high respect on the individuality of each student and recognizing the individualization of the process and the many different learning styles involved. To accomplish this, we will create a learning environment which is intellectually challenging, highly professional, and emotionally safe. 
Goals

․ The individual transformation of the cognitive and emotional being (the whole person) Creation of educational opportunities for all kinds of people.

While we knew we were being lofty in our vision and goals, we thought the literature on the adult student demanded that we set our standards high.

\section{Development of an Agenda for the Orientation}

Given our many discussions on the difficulty of teaching adult students, it was thought that many of our faculty would appreciate an introduction and discussion on the history of adult education and the adult student characteristics as described by much of the literature. This then made up the initial period for each workshop/orientation program. In addition, given the resistance to shortened terms, emphasis was placed on a rationalization/discussion of why this accelerated approach worked for adult students. This led easily into the development of the cohort approach and the need for establishing a sense of community for the adult student. Throughout each orientation, a lively discussion about the adult student and his/her history sprung up. The remaining time was spent on discussing appropriate pedagogical styles for cohort-based adult programs.

\section{The Adult Student}

Throughout our history, many Americans have developed a faith that our educational system allows each individual, regardless of class or color, an equal opportunity to advance his/her station in life (Rudolph, 1990). Yet, access has been limited. Many barriers exist: economic, political, or social. A multiplicity of factors affect the success of adult students leading many to imagine that adult students are caught in a cycle of failure and can never be truly successful in attaining a college degree since their knowledge, experiences and abilities do not equal those of traditional students.

These adults return to school while fulfilling multiple roles: parent, employee, daughter/son, wife/husband. Further, many researchers contend that it is life transitions that first impels them to return to school, the most common of which involve career or family (Aslanian and Brickell, 1980, Schlossberg et al., 1989). As a result, the adult student is seen as being primarily off-campus centered and not interested in developing a sense of community within the campus. While most theories of student persistence and success assert that student involvement in the campus community is a strong predictor of success, the adult student's involvement on campus and his/her perspective on the college experience are very different from that of the traditional student (Astin, 1977, 1993; Knowles, 1980; Tinto, 1987; Naretto, 1995; Chickering and Reisser, 1993).

Adult students make up nearly $50 \%$ of all college enrollments. However, after a time, those who feel they do not "fit in" withdraw. Tinto's (1987) model of disengagement blends elements of cost-benefit analysis and Durkheim's theory of egoistic suicide to explain the "push and pull" of external factors. This model asserts that withdrawal is most influenced by the background characteristics that affect a student's ability to integrate socially. The model, however, also emphasizes an interactionist aspect:

In focusing on the multiple interactions which occur among members of the institution, the model is also primarily social in character. That is, it looks to the social and intellectual context of the institution, its formal and informal interactional environment, as playing a central role in the longitudinal process of individual departure. Though it accepts as a given the fact that individuals have much to do with their own leaving, it argues that the impact of individual attributes cannot be understood without reference to the social and intellectual context within which individuals find themselves.... The communities of the college mediate, if not transform, the effect of the formal organization upon student behavior (Tinto, 1987, p. 113).

Tinto's (1987) interactive perspective and emphasis on the social aspect of the model links back to the dialectical perspective of such theorists as Kegan (1982) and Basseches (1984). Their approach emphasizes 
interactive and constitutive relationships. MacKinnon-Slaney (1994) suggests three factors influence this interactive or social aspect or the adult's ability to feel as though he/she "fits" into the learning environment: the adult student's own sense of self; the ability of the adult to retrieve information from the institution; and the adult's perception of compatibility with the learning environment (Luke, 2002). If their needs are not met, these students will leave. Thus, it is important for the faculty who teach in these programs to recognize that these are students who demand respect, want the teacher to be on time, and expect other students to contribute. Their individual goals are to leave with information sufficient to help them improve their lives. They have accepted the need to integrate their already attained learning with that to be gained within the academy. If the educational environment is good, it will create these interactive and constitutive relationships.

To be considered of importance is that these adult students' backgrounds vary -- with many having experienced a major trauma prior to returning to school: death of a family member, divorce, loss of a job, abuse. Work experience also covers the gamut with some having attained executive positions and others working on the factory floors. Family experiences as well as previous educational experiences bring a broad array of perspectives to each cohort. Degrees of integration, Tinto (1987) believed, plus levels of institutional and goal commitment can equal persistence and thus success for the adult student. Many adult educators agree this sense of commitment needs to come from all involved: the student, his/her peers, the institution, and the individual and collective faculty. Jarvis (1992) and others emphasized the importance of the faculty/student connection. The committee agreed with this perspective. Further, we believed the faculty member had the most influence on the establishment of a positive classroom environment by effectively integrating these many and varied experiences.

\section{The Cohort and Accelerated Learning}

The cohort experience, if facilitated well, can be a powerful force from which to leverage this needed commitment from the individual student, his/her peers, the college, and teacher/facilitator. The classroom, then, truly becomes where the social and academic meet (Tinto, 1997). The experience brought into these closed communities calls for faculty who are willing to seek to understand the vast and varied backgrounds and experiences contained in each cohort. What is required is not one who can deliver knowledge but one who can facilitate the recognition and integration of new knowledge. Integration then becomes not something we simply do between courses but within each class experience. The adult classroom brings to it a vast panorama of experiences: professional, social, and psychological. This latter also brings with it the challenge of dealing with varied issues of self-esteem and learning styles.

What at first appears to be a challenge may also be an opportunity. Facilitated well, the cohort experience allows each student and each faculty member to question how we know what we know. As faculty, we must set up opportunities that allow the student to question their own perspectives through reflection on their own experiences as well as the experiences of those within the cohort. As faculty establish this environment, the four stages of group development need to be recognized and addressed: forming, storming, norming and performing. What we can offer is an opportunity to truly change the context of the students' own experiences through an integration process, one that challenges them to integrate their past with that of others within their new family, the cohort. The emphasis is on process. Now, we no longer ask them to merely acquire data. Rather, we challenge them to consider their own meaning schemes and perspectives by differentiating and integrating their experiences with that of their classmates. The group process allows gradual changes to occur both within the cohort as well as within individuals who must work within the structures and practices to support the collective mission and goals. If the cohorts' goals are to be met, most often this process facilitates changes in perspectives. Mezirow (1984) considers this idea of changing perspectives by suggesting a sequence of qualitative changes through developmental experiences involving "a series of perspective transformations in understanding oneself and one's relationship" (p. 123). The cohort then offers the student the opportunity to explore through varied courses not only their own perspectives but also those of their peers and their faculty. 


\section{Pedagogical Considerations}

Following a lively discussion on the adult student and the cohort experience, faculty were asked to consider what instructor behaviors they would ideally witness in the program's classroom and what instructor behaviors they would typically witness in a "traditional" undergraduate instructional setting. They then compared and contrasted these answers and discussed the implications. Participants at each workshop were asked to consider their own values, beliefs, assumptions, history, and needs. Varied exercises were offered to aid them in recognizing their own perspectives and the impact those perspectives had on their behavior as facilitators. For example, here the Johari Window was introduced. The orientation then moved into varied exercises utilized to develop trust among the cohort members as well as to enhance the individual's ability both to communicate their own perspectives and to hear that of others.

Through varied pedagogical approaches at each workshop, we attempted to cover the following:

$\begin{array}{ll}\square & \text { Establishing a Climate for Learning } \\ \square & \text { Group Development } \\ \square & \text { Content Versus Process } \\ \square & \text { The Dimensions of Process } \\ \square & \text { Maintaining Participation } \\ \square & \text { Focusing Discussion } \\ \square & \text { Clarifying Points of Confusion } \\ \square & \text { Adapting to the Cohort's Needs } \\ \square & \text { Conflict Management }\end{array}$

It was evident, as we developed this orientation, that there was much to cover. Further, even veteran faculty could benefit by an on-going opportunity to develop their own teaching skills. What better way to do that then to share their experiences with new and evolving faculty. Thus, we decided to require a rotating presence within each workshop for all faculty. What we hoped to produce was a model cohort from which faculty could learn and transfer this experience of "being in" the cohort rather than merely teaching or facilitating a cohort. Towards the end of the orientation/workshops, participants were asked to identify up to three errors each may have made as an instructor, which each believed contravened good practice as a facilitator. Each was given a $3 \times 5$ card and told not to place his/her name on the cards. These were shared anonymously. The examples were numerous:

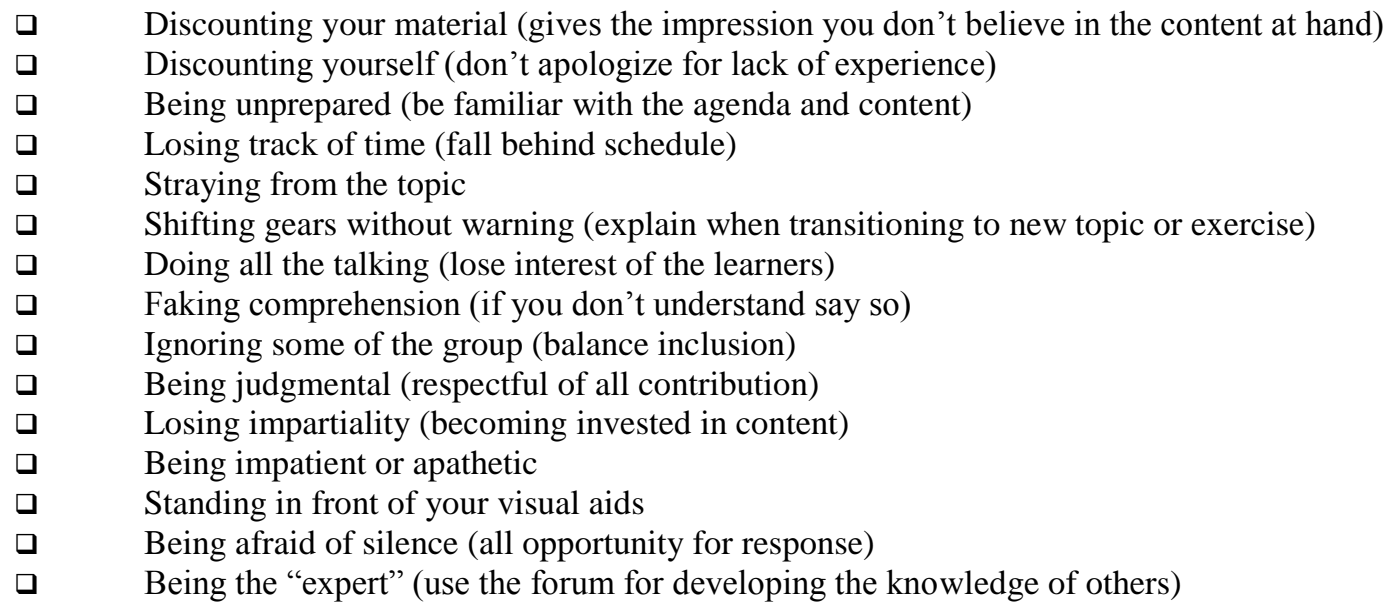

At the end of each session, to provide the workshop facilitators feedback and in the spirit of on-going renewal, participants were asked to examine their notes from the workshop and to answer the following:

Were expectations met? 


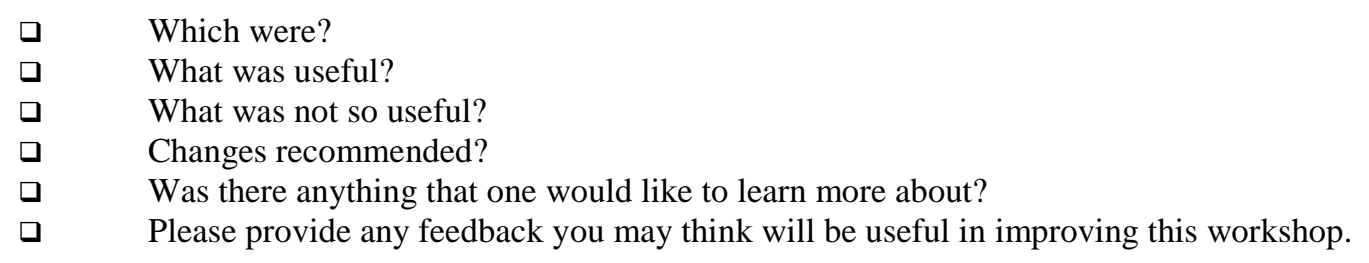

\subsection{Conclusion}

While there was resistance during the early months as this program evolved, the committee and leaders of the program gradually heard from more veteran faculty and students within the program that the development of this workshop had accomplished several goals:

a culture of on-going renewal had been developed;

口 A camaraderie had developed among committed faculty;

a Much was learned about the adult student's background and varied experiences;

口 Pedagogical styles were shared and classroom experiences became more consistent across the program;

口 Curriculum became more integrated with faculty members from varied disciplines sharing their knowledge while also learning from their fellow faculty members from other disciplines and backgrounds.

We hoped that we had provided insight about ways in which teachers could enhance the cohort experience and thus influence both persistence and learning. We had essentially created our own "team". The experience and the resulting pedagogical changes which became evident showed us that we could build supportive peer groups; share learning by bridging the academic and social divide; and provide a voice to students in the construction of knowledge. The adult educator, Lindeman, had long ago suggested that the process of group learning could support social action and social change (Rose, 1996). While such change begins with the individual, it is often empowered through the group experience. Our own group of administrators and faculty had empowered the changes we were seeing. The cohorts we watched evolve clearly learned to support the growth of each student within while simultaneously supporting the growth of the cohort. For each cohort that managed this, individuals and whole groups were successful. Our hope was that this academic experience helped transform their external personal and professional experiences. For the faculty involved, we know that it did. For with each cohort, we learned; we explored our own perspectives, and we evolved.

\subsection{Bibliography}

1. Aslanian, C. B. a. H. M. B. (1980). Americans in transition. New York: College Entrance Examination Board.

2. Astin, A. (1977). Preventing students from dropping out. San Francisco: Jossey-Bass Publishers.

3. Astin, A. W. (1993). Assessment for excellence. American Council on Education: MacMillan Publishing.

4. Basseches, M. (1984). Dialectical thinking and adult development. Norwood, NJ: Ablex Publishing Corp.

5. Chickering, A. W., \& Reisser, L. (1993). Education and identity. San Francisco: Jossey-Bass Publishers.

6. Gardner, H., \& Hatch, T. (1990). Multiple intelligences go to school: Educational implications of the theory of multiple intelligences (Tech. Rep. 4). Cambridge: Harvard.

7. Jarvis, P. (1992). Paradoxes of learning. San Francisco: Jossey-Bass Publishers.

8. Kegan, R. (1982). The evolving self. Cambridge: Harvard University Press.

9. Kett, J. F. (1994). The pursuit of knowledge under difficulties. Stanford California: Stanford University Press.

10. Knowles, M. (1980). The modern practice of adult education. Chicago: Follett Publishing Company.

11. Luke, G. F. (2002). An inquiry into the factors influencing the success of the underprepared adult student. Unpublished Dissertation, University of Massachusetts, Boston.

12. MacKinnon-Slaney, F. (1994). The adult persistence in learning model: A road map to counseling services for adult learners. Journal of Counseling \& Development, 72(January/February). 
13. Mezirow, J. (1984). A critical theory of adult learning and education. In S. Merrian (Ed.), Selected writing on philosophy and adult education (pp. 18). Malabar, Florida: Robert E. Krieger Publishing Company.

14. Naretto, J. A. (1995). Adult student retention: the influence of internal and external communities. NASPA, Vol. 32, No. 2(Winter), p. 90-97.

15. Pascarella, E. T., \& Terenzini, P. (1994). How college affects students. In K. A. Feldman \& M. B. Paulsen (Eds.), Teaching and learning in the college classroom (pp. 577-595). Needham Heights: Simon and Schuster.

16. Rose, A. D. (1996). Group learning in adult education: its historical roots. New Directions For Adult and Continuing Education, 71(Fall 1996), 13.

17. Schlossberg, N. K., Lynch, Ann Q., and Arthur W. Chickering. (1989). Improving higher education environments for adults. San Francisco: Jossey-Bass Publishers.

18. Tinto, V. (1987). Leaving college. Chicago: The University of Chicago Press.

19. Tinto, V. (1997). Classrooms as communities. Journal of Higher Education, 68(6), 599-623. 